UDC: 616-083.98-089.5-052-056.25(043.3)

DOI: $10.15587 / 2519-4798.2020 .213824$

\title{
DYNAMICS OF LEPTIN, INSULIN RESISTANCE, PARATHYROID HORMONE, 25(OH)D IN THE IMPLEMENTATION OF THE ERAS-PROTOCOL IN PATIENTS OF SURGICAL PROFILE
}

\section{H. Diachenko, Yu. Volkova}

The aim: to increase the effectiveness of treatment of patients of surgical profile with overweight by developing algorithms for perioperative intensive care for the successful implementation of the ERAS protocol.

Material and methods. The basis of this study is the analysis of the results of a comprehensive clinical and instrumental dynamic examination of 122 patients with surgical herniological profile for a period of 1 day to 1 month from the date of surgery. The study included patients with ventral hernias of the anterior abdominal wall, which were determined by the SWR classification. The conditions for admission to the study under the conditions of inclusion were a fence 10 days before surgery to determine the analysis of vitamin D concentration. 3 groups of patients were identified (control, with addition to the protocol of treatment of cholecalciferol, with addition to the protocol of treatment of cholecalciferol and a solution of D-fructose-1,6-diphosphate sodium salt of hydrate). Determined the type of fat distribution, index of visceral obesity, triglycerides, high-density lipoprotein, leptin, fasting glucose, endogenous insulin, calculated the index of HOMA. Parametric statistics methods were used to process the obtained data.

Results. In the vast majority of overweight patients (90\%) the abdominal type of fat distribution with the presence of visceral index obesity was determined. At the time of screening, the concentration of leptin in the blood of all studied patients exceeded the upper limit of normal by almost 4 times. The absence of a probable connection between the level of 25 (OH) D and leptin was determined, which confirms the presence of obesity due to reduced muscle mass and impaired energy metabolism, the presence of a relationship between the level of 25 (OH) D, HOMA, concentration of parathyroid hormone in the blood.

Conclusions. Implementation of a planned surgical profile in overweight patients at the screening stage 10 days before surgery to determine the level of $25(\mathrm{OH}) \mathrm{D}$ in the blood is a key point in deciding the possibility of conducting the perioperative period according to the ERAS program. Additional purpose to its classical protocol of cholecalciferol and solution of D-fructose-1,6-diphosphate sodium salt of hydrate increases the quality of motor activity of patients after surgery, increases their adaptive potential by restoring lost muscle function. The optimized classical algorithm of the ERAS-program significantly $(p<0.05)$ improved the quality of life in the long term $(30$ days after surgery), such as physical functioning, general health, viability scale, mental health (SF-36 scale) and decreased body mass index

Keywords: sarcopenic obesity, vitamin D, ERAS-program, cholecalciferol, leptin, quality of life, prognosis

Copyright (C) 2020, H. Diachenko, Yu. Volkova.

This is an open access article under the CC BY license (http://creativecommons.org/licenses/by/4.0).

\section{Introduction}

According to some researchers, the functions of vitamin D (VD) are not limited to the control of calcium-phosphorus metabolism, it also affects other physiological processes in the body, including modulation of cell growth, neuromuscular conduction, immunity and inflammation $[1,2]$. In turn, many studies of the last decade have convincingly proven that the human body with sufficient vitamin D (VD) not only affects the condition of the skeleton and muscle tissue, but also significantly determines the quality of disease prevention of other organs and systems [3, 4].

The literature describes possible mechanisms by which excess adipose tissue can reduce the concentration of VD circulating in the blood [5,6]. One of them is a sedentary lifestyle of obese patients, which leads to a decrease in insolation time and reduced formation of cholecalciferol in the skin compared to people with normal body weight $[7,8]$. In addition, it was found that in conditions of excess body weight there is a deposition of $25(\mathrm{OH}) \mathrm{D}$ in adipose tissue and a decrease in the concentration of VD circulating in the serum. In addition, the catabolism of VD in adipose tissue increases with the formation of its inactive form - 24,25-dihydroxyvitamin D [9, 10]. Finally, obesity leads to the development of non-alcoholic liver disease, which causes a decrease in the rate of synthesis of $25(\mathrm{OH}) \mathrm{D}$ in hepatocytes $[11,12]$.

In recent years, it has been established that adipose tissue is an independent active endocrine organ in which adipokines (hormones) are formed, including leptin, a leading biologically active agent $[13,14]$. It is known that in conditions of hyperleptinemia there is hyperinsulinemia, endothelial dysfunction, hypertrophy of vascular wall cells, accumulation of cholesterol esters in foam cells, increase in the content of acute phase proteins, decrease in cholesterol levels, lipoproteins and high activity. Important is the fact that leptin has a negative effect on the enzymes of the final synthe- 
sis of VD in the kidneys and peripheral, including adipose tissue $[17,18]$.

Thus, modern scientific data suggest that obesity can reduce the formation of VD, its deposition and accelerated destruction in adipocytes, which can lead to a decrease in its bioavailability and the development of insufficiency and deficiency $[19,20]$. However, it is believed that low VD contributes to obesity and/or prevents weight loss [21, 22], and waist circumference, considered by IDS (Immunology of Diabetes Society) as an important diagnostic criterion for metabolic syndrome and is a surrogate indicator of abdominal obesity, has been proven by many researchers the relationship between the level of VD in the blood and the type of obesity [23, 24].

Given the above facts, before planning the study, we anticipated a possible violation of VD metabolism in overweight patients who planned elective surgery for primary ventral hernia of large and giant size. Since the most common cause of this pathology without prior surgery on the abdominal organs in the anamnesis is the weakness of the muscular skeleton of the anterior abdominal wall, these changes could occur in so-called sarcopenic obesity, when adipose tissue accumulates instead of muscle loss at low BMI figures.

The aim of the study was to increase the effectiveness of treatment of patients with surgical profile with overweight by developing algorithms for perioperative intensive care for the successful implementation of the ERAS protocol.

\section{Materials and methods}

The basis of this study is the analysis of the results of a comprehensive clinical-instrumental and laboratory dynamic examination and evaluated the effectiveness of the proposed method of prevention and treatment in a cohort prospective randomized open clinical study in 122 patients with surgical herniological profile for a period of 1 day to 1 month, carrying out surgical interventions that were treated at the Municipal Non-Commercial Enterprise "City Clinical Hospital of Ambulance and Emergency Care named after prof. O. I. Meshchaninov" of the Kharkiv City Council in the period 2016-2020. Ethical aspects of the work were approved at a meeting of the commission on biomedical ethics of the Kharkiv National Medical University of the Ministry of Health of Ukraine (Minutes No. 8 of December 10, 2019). All patients signed an informed consent to participate in the study.

The study was conducted by random sampling. Patients of all groups were examined before surgery in accordance with the unified clinical protocol approved by the Ministry of Health of Ukraine, which was adapted to the ERAS program. The anamnesis was carefully studied, in particular the postponed surgical interventions, features of the premorbid background, concomitant diseases, use of drugs. The study included patients with ventral hernias of the anterior abdominal wall, which were determined by the classification of J. P. Chevrel and A. M. Rath (SWR classification) (1999).

The conditions for selecting patients for the study were age 18-60 years, increased BMI (25.0-29.9) lasting more than 10 years, the presence of primary ventral hernia, obtaining informed consent, the absence of severe metabolic and somatic acute and chronic diseases, including number of kidney diseases, absence in the anamnesis of blood diseases, oncological diseases, aggravated heredity, alcoholism, mental disorders, allergic reactions, blood transfusions, use of immunocorrectors, glucocorticoid drugs, uniformity of examination, diagnosis and preoperative preparation of the patient, condition of patients on the ASA scale - II $-100 \%$ of patients.

All patients were screened 10 days before surgery. The conditions for admission to the study under the conditions of compliance with the inclusion criteria were a fence 10 days before the operation of the blood to determine the analysis for the concentration of VD.

Exclusion criteria were age 18 and over 60, consultation with an endocrinologist for hyperlicemia, consultation with a dietitian or family doctor about weight gain, daily medication for any comorbidities, the patient's disagreement with the study. In order to randomize patients, anesthesia and surgical treatment were taken into account, including the size of the hernia and the degree of degenerative changes in the abdominal wall, which can lead to complications. General characteristics of patients are given in Table 1.

Table 1

General characteristics of patients, $n=122, M \pm \sigma$

\begin{tabular}{|c|c|}
\hline Indicator & Value \\
\hline Age, years & $54.2 \pm 5.9$ \\
\hline Body weight, $\mathrm{kg}$ & $91.6 \pm 8.9$ \\
\hline Height & $175.2 \pm 12.1$ \\
\hline BMI & $28.1 \pm 1.7$ \\
\hline Duration of anesthesia, $h$ & $2.06 \pm 0.04$ \\
\hline Duration of operation, $h$ & $2.29 \pm 0.19$ \\
\hline
\end{tabular}

The diagnosis of primary ventral abdominal hernia was made on the basis of medical history, clinical signs and instrumental examination, which included: ECG, chest radiography, abdominal ultrasound, computed tomography, MRI. The distribution of patients by anatomical location and width of the hernia gate according to the classification of SWR (J. P. Chevrel, A. M. Rath, 1999) are presented in Table 2.

Patients were divided into 2 groups according to the principle of use in the algorithm of perioperative ERAS-program of additional drugs that have protective properties in case of sarcopenic obesity in patients.

Group II included 44 patients who were given $7,000 \mathrm{IU} /$ day of vitamin D (cholecalciferol) ("Vigantol" 14 drops/day) 10 days before the planned surgery; under the conditions of determination of VD deficiency - blood concentration $<30 \mathrm{ng} / \mathrm{ml}-7000 \mathrm{IU} /$ day of vitamin D (cholecalciferol) ("Vigantol" 14 drops/day) was prescribed for therapeutic purposes for 10 days with subsequent transition to prophylactic doses - $1000 \mathrm{MO}$ ("Vi- 
gantol" 2 drops/day) daily for a long period under the control of body weight and vitamin D levels in the blood. The frequency of use was due to the pharmacodynamics of the drug - it is known that the maximum concentration of $25(\mathrm{OH}) \mathrm{D}-\mathrm{VD}$ - in serum is observed 12 hours after a single dose and returns to baseline after 72 hours. The threshold value for inclusion of the patient in the study, namely the level of $25(\mathrm{OH}) \mathrm{D}$ in the blood $<30 \mathrm{ng} / \mathrm{ml}$ was determined on the basis of data from modern medical professional organizations [22].

Table 2

Division of patients by type of ventral hernia (by J. P. Chevrel and A. M. Rath (1999, SWR classification))

\begin{tabular}{|c|c|c|c|}
\hline Indicator & $\begin{array}{c}\text { Group I, } \\
\mathrm{n}=32\end{array}$ & $\begin{array}{c}\text { Group II, } \\
\mathrm{n}=44\end{array}$ & $\begin{array}{c}\text { Group III, } \\
\mathrm{n}=46\end{array}$ \\
\hline \multicolumn{4}{|c|}{ Anatomical localization on the abdominal wall - middle (M) } \\
\hline $\begin{array}{l}\text { M1 - above the umbilical } \\
\text { cord }\end{array}$ & $15(47 \%)$ & $19(44 \%)$ & $21(46 \%)$ \\
\hline $\begin{array}{c}\text { M2 - near the umbilical } \\
\text { cord }\end{array}$ & $12(38 \%)$ & $15(34 \%)$ & $18(39 \%)$ \\
\hline $\begin{array}{l}\text { M3 - under the umbilical } \\
\text { cord }\end{array}$ & $3(9 \%)$ & $7(15 \%)$ & $5(11 \%)$ \\
\hline $\begin{array}{l}\text { M4 - in the area of the } \\
\text { xiphoid process or womb }\end{array}$ & - & - & - \\
\hline \multicolumn{4}{|c|}{ Anatomical localization on the abdominal wall - lateral (L) } \\
\hline L1 - hypochondrium & $1(3 \%)$ & $2(5 \%)$ & $1(2 \%)$ \\
\hline $\mathrm{L} 2$ - transverse & $1(3 \%)$ & $1(2 \%)$ & - \\
\hline L3 - iliac & - & - & - \\
\hline L4 - transversalis & - & - & $1(2 \%)$ \\
\hline \multicolumn{4}{|c|}{ The width of the hernia gate $-(\mathrm{W})$} \\
\hline $\mathrm{W} 1-5 \mathrm{~cm}$ (small hernia) & - & - & - \\
\hline $\begin{array}{c}\mathrm{W} 2-5-10 \mathrm{~cm} \text { (hernia of } \\
\text { medium size) }\end{array}$ & $6(19 \%)$ & $9(20 \%)$ & $8(17 \%)$ \\
\hline $\begin{array}{c}\mathrm{W} 3-10-15 \mathrm{~cm} \text { (hernia } \\
\text { of large size) }\end{array}$ & $21(66 \%)$ & $27(62 \%)$ & $32(70 \%)$ \\
\hline $\begin{array}{l}\mathrm{W} 4 \text { - more than } 15 \mathrm{~cm} \\
\text { (giant hernia) }\end{array}$ & $5(15 \%)$ & $8(18 \%)$ & $6(15 \%)$ \\
\hline \multicolumn{4}{|c|}{ The presence and number of recurrences $(\mathrm{R})$ after hernioplasty } \\
\hline R0 & 32 & 44 & 46 \\
\hline
\end{tabular}

Group III included 46 patients who were prescribed $7,000 \mathrm{IU} /$ day of vitamin D (cholecalciferol) for treatment 10 days and then 10 days before the planned surgery in terms of determining the deficiency of VD - blood concentration $<30 \mathrm{ng} / \mathrm{ml}$ transition to prophylactic doses 1000 IU daily for a long period under the control of body weight and vitamin D levels in the blood. Also to the IT algorithm patients of group III were assigned a solution of D-fructose-1,6-diphosphate sodium salt of hydrate intravenously $150 \mathrm{mg} / \mathrm{kg}$ of ideal body weight 2 times a day at a rate of $10 \mathrm{ml}$ per minute every night for the first 3 days of the postoperative period. the same input mode.

Control group I consisted of 32 patients who were admitted to the hospital for elective surgery for primary ventral hernia, all criteria coincided with patients of groups II and III, but did not have in the complex of perioperative intensive care additional drugs to promote the full implementation of ERAS-program.

Prior to inclusion in the study, each patient received informed consent, in which the control points of the examination were the day 10 days before surgery, the 1st, 2nd, 3rd day of hospital stay, as well as the possibility of an active outpatient visit (contact by phone) for 30 days after surgery. At these stages, patients' gait quality, the number of days spent in the hospital after surgery, and indicators were recorded, which, according to many researchers, may hinder the timely implementation of the ERAS program. Thirty days after surgical treatment of primary ventral hernia, all subjects underwent an active outpatient visit (telephone call) to assess their quality of life on the SF-36 questionnaire.

Blood for the study in patients was taken on an empty stomach at 8.00 am on the appropriate day. The scheme included a study of clinical analysis of blood, blood triglycerides, high-density lipoprotein, leptin, fasting glucose, endogenous insulin, inorganic phosphorus, parathyroid hormone. The duration of physical activity of patients was assessed daily - determined the average speed and pace, the total length of the track, which was overcome by patients during their hospital stay. To do this, each patient had an activity tracker (pedometer) from Joyzy (China) on his left ankle.

In addition to the absolute results of the studied markers, their ratio to the indicators in the control groups and to the average starting figures in each of the groups separately. The connections of these indicators with the influence of substances that were proposed as additional in groups II and III in order to prevent complications in the postoperative period were studied.

Given that all patients who participated in the study were overweight, i.e. BMI was in the range of 25.0-29.9, it was important to determine the type of distribution of adipose tissue, which was carried out on the index of waist volume (WV)/ thigh volume (TV): the gluten-femoral type of distribution corresponded to an index of less than 0.85 ; abdominal type of distribution - more than 0.85 (WHO, 1997): measured WV in the supine position in the middle of the distance between the top of the iliac crest and the lower lateral edge of the ribs. BMI was calculated by the formula proposed by A. J. Quetelet in 1835 and approved by the WHO as the Kettle index:

\section{BMI=body weight $(\mathrm{kg}) /$ height $^{2}\left(\mathrm{~m}^{2}\right)$.}

Visceral obesity index (VOI) - index of visceral adipose tissue function and insulin sensitivity, was determined by the formula:

Men: $\mathrm{VOI}=(\mathrm{WV} / 39.68+$

$+(1.88 \cdot \mathrm{BMI})) \cdot(\mathrm{TG} / 1.03) \cdot(1.31 / \mathrm{HDL})$; 
Women: $\mathrm{VOI}=(\mathrm{WV} / 39.58+$

$+(1.89 \cdot \mathrm{BMI})) \cdot(\mathrm{TG} / 0.81) \cdot(1.52 / \mathrm{HDL})$.

VOI=1 for healthy patients with normal BMI, adipose tissue distribution, high-density lipoprotein (HDL) cholesterol and triglycerides (TG); age norms: VOI: $<30$ years $-2.52 ; 30-42$ years $-2.23 ; 42-52$ years -1.92 ; $52-66$ years $-1.93 ;>66$ years -2.0 .

To determine the changes in the body that accompany the increased amount of visceral adipose tissue, determined the level of triglycerides (TG), high-density lipoprotein (HDL), leptin, fasting glucose, endogenous insulin, calculated HOMA index (insulin resistance (IR)).

The study of TG and HDL concentration was performed by colorimetric photometric method on an automatic biochemical analyzer COBAS INTEGRA 400/ 700/800 (Germany). The level of leptin was determined by enzyme-linked immunosorbent assay using test systems "Leptin ELISA" Diagnistics Biochem, Canada, reference interval (RI) - women 3.7-11.1 ng/ml, men $2.0-5.6 \mathrm{ng} / \mathrm{ml}$; the concentration of endogenous insulin was determined by enzyme-linked immunosorbent assay using test systems "EIA-2935 ELISA", DRG, Germany; fasting glucose levels were determined by the hexokinase method; IR level assessment was performed using a homeostasis model assessment model,

$\mathrm{HOMA}=\mathrm{EI}(\mu \mathrm{IU} / \mathrm{ml}) \times \mathrm{GN}(\mathrm{mmol} / \mathrm{l}) / 22.5, \mathrm{RI}>2.86$.

The content of VD $(25(\mathrm{OH}) \mathrm{D})$ in the blood was performed by immunochemiluminescence method on the analyzer Abbott Architect 8000, USA, RI rate - more than $30 \mathrm{ng} / \mathrm{ml}$, insufficiency - 20-30 ng/ml, deficiency - less than $20 \mathrm{ng} / \mathrm{ml}$. Parathyroid hormone level (PTH) in the blood was determined by immunochemiluminescence using a Liaison analyzer (DiaSorin, Italy), RI 15.0-65.0 pg/ml.

Methods of parametric statistics were used to process the obtained data (Glanz S., 1999). Statistical processing of data entered in Excel spreadsheets was performed. The significance of the obtained data was checked using Student's t-test (for $\mathrm{n}<100$ ) at a given level of reliability $\mathrm{p}=0.95$. To be able to use the Student's t test, the Fischer-Snedecor test was calculated - the ratio of the larger variance to the smaller. All mathematical operations and graphical constructions were performed using the software packages "Microsoft Office XP": "Microsoft XP Home" and "Microsoft Excel XP" on a personal computer.

\section{Research results}

Before planning the study, we anticipated a possible violation of VD metabolism in overweight patients who were scheduled for planned surgery for primary ventral hernia of large and giant size. Since the most common cause of this pathology without prior surgery on the abdominal organs in the anamnesis is the weakness of the muscular skeleton of the anterior abdominal wall, these changes could occur in so-called sarcopenic obesity, when adipose tissue accumulates instead of muscle loss at low BMI figures. Therefore, to determine the type of adipose tissue distribution in all patients, we determined before surgery VOI, which was in our study as a leading screening marker due to the ability to determine a certain advantage of visceral fat over subcutaneous. The vast majority of overweight patients who underwent preoperative screening to determine the type of adipose tissue distribution had elevated VOI. Thus, in group I glute-femoral type of distribution was in 2 (6\%), abdominal - in 30 (94\%), in group - II gluteo-femoral type of distribution was in $3(7 \%)$, abdominal - in 41 (93\%), in group III - gluteo-femoral type of distribution was in 3 (7\%), abdominal - in 43 (93\%) patients, respectively. Thus, it can be argued that, despite being overweight and having a BMI range of $28.1 \pm 1.7$, more than $90 \%$ of subjects had an abdominal type of fat distribution, with VOIs in each group indicating obesity.

Taking into account the obtained data, as well as the direct proportional dependence of leptin content in the blood on the amount of adipose tissue, it was important to determine its blood level in patients of groups I, II and III at the screening stage, as well as at 1st, 2nd and 3rd day of stay in the hospital.

First, we determined the starting level of leptin, which was carried out 10 days before surgery. Thus, in patients of group I its concentration was $33.4 \pm 6.2 \mathrm{ng} / \mathrm{ml}$, groups II and III $34.7 \pm 8.1 \mathrm{ng} / \mathrm{ml}$ and $33.9 \pm 5.3 \mathrm{ng} / \mathrm{ml}$, respectively. In this case, given the absence of probable differences between groups in terms of leptin levels in the blood, we calculated its average indicator between groups and took it as the average starting level, which corresponded to $34.0 \pm 6.5 \mathrm{ng} / \mathrm{ml}$. Therefore, at the time of screening, the concentration of leptin in the blood of all studied patients exceeded the upper limit of normal by almost 4 times. Subsequently, in group I on the 1st, 2nd and 3rd day of treatment, this figure was $34.7 \pm 6.1,35.1 \pm$ $\pm 5.1 \mathrm{ng} / \mathrm{ml}$ and $34.2 \pm 5.8 \mathrm{ng} / \mathrm{ml}$, respectively, which almost coincided with the average starting values. In turn, in groups II and III, despite significant differences in the metabolic component of perioperative intensive care, during the first three days of inpatient treatment no statistically significant differences were found between the rate of leptinemia in the blood of patients in any case. Thus, on the 1st, 2nd and 3rd days of treatment the level of leptin in the blood of the subjects of group II was $34.8 \pm 7.1 \mathrm{ng} / \mathrm{ml}, 35.4 \pm 6.2 \mathrm{ng} / \mathrm{ml}$ and $34.9 \pm 7.3 \mathrm{ng} / \mathrm{ml}$, respectively; in group III on the 1st, 2nd and 3rd day of intensive care, the concentration of this adipose tissue hormone was $34.4 \pm 5.3 \mathrm{ng} / \mathrm{ml}, 34.1 \pm 5.9 \mathrm{ng} / \mathrm{ml}$ and $35.2 \pm$ $\pm 7.1 \mathrm{ng} / \mathrm{ml}$, respectively. In this case, given the circadian dependence of leptin secretion, in no case was a statistically significant difference between the values of this indicator, even deviations of $5 \%$. Thus, it can be noted that, despite the BMI - 25.0-29.9, when patients are diagnosed with overweight, given the duration of weight gain of more than 10 years in the anamnesis, all subjects can be considered the presence of "leptin resistance", i. e. distortion of adipose tissue hormone metabolism with corresponding pathogenetic changes.

When analyzing the obtained data by studying the dynamics of leptin in the blood of overweight patients 
who were treated with ERAS-program for surgery for primary ventral hernia, we obtained data indicating the lack of connection between VD and leptin in the form of inhibitory effect of VD on leptin secretion by adipose tissue, which confirms the presence of obesity due to reduced muscle mass, impaired energy metabolism and is important in determining the optimal complex of perioperative intensive care.

To determine the fact of insulin resistance in all studied patients, we determined its starting level, which was carried out 10 days before surgery using HOMA indices.

Thus, in patients of group I the HOMA index was $3.8 \pm 0.8$, groups II and III $3.7 \pm 0.6$ and $3.8 \pm 0.7$, respectively. In this case, taking into account the absence of probable differences between the groups in terms of its figures, we calculated their average display between the groups and took it as the average starting level, which corresponded to $3.8 \pm 0.7$. Thus, it can be noted that at the time of screening the figure, the HOMA index in all studied patients exceeded the reference interval $-2.86-1.5$ times. Subsequently, in group I on the 1st, 2nd and 3rd day of treatment, this figure was $3.8 \pm 0.8,3.8 \pm 0.4$ and $3.8 \pm 0.6$, respectively, which almost coincided with its average starting values.

In turn, in group II, a decrease in the level of IR during the first three days in relation to baseline values and in relation to its daily level in the subjects of group I, which was $3.1 \pm 0.6,2.9 \pm 0.4$ (probable $(\mathrm{p}<0.05)$ decrease in relation to the values of this indicator in group I) and $2.9 \pm 0.1$ (probable $(\mathrm{p}<0.05)$ decrease in relation to the values of this indicator in group I and to the starting values) on the 1st, 2nd and 3rd days of treatment, respectively. In group III on the 1st day of hospital stay the IR level was $2.9 \pm 0.4$, which was 1.5 times less than at the screening stage and on the 1st day of treatment, on the 2nd and $3 \mathrm{rd}$. On the second day of the postoperative period, the IR values were $2.9 \pm 0.1$ and $2.9 \pm 0.1$, respectively, and were probably $(p<0.05)$ lower relative to the level of this indicator in group I and to its initial values.

There was no significant difference between the level of IR in the blood of the studied groups II and III. When analyzing the data obtained by studying the level of IR in overweight patients who were treated with ERAS-program for surgery for primary ventral hernia, we obtained data indicating a possible link between VD and IR level, which is possible as a secondary effect of inhibition of leptin secretion by adipose tissue on the background of additional administration of VD, which is important in determining the optimal complex of perioperative intensive care. Given the preliminary data obtained in determining the type of fat distribution using the calculation of VOI, leptin concentration in the blood and IR level, it becomes clear the effect of VD in serum on predicting the implementation of the accele rated recovery program in overweight patients schedul ed for surgery for primary ventral hernia.

Given the fact that in almost all patients we studied on the background of overweight, BMI 28.1 \pm 1.7 , at the screening stage revealed an increase in leptin concentration in the blood and its dynamics during the first three days of the postoperative period, the value of the index HOMA, which exceeded the reference interval, and their dynamics during the hospital stay, and taking into account the fact of duration of weight gain in all patients more than 10 years (history), we analyzed the level of $25(\mathrm{OH}) \mathrm{D}-$ (total level of $\mathrm{D}_{2}$ (endogenous, ergocalciferol) and $\mathrm{D}_{3}$ (endogenous, cholecalciferol) - in the blood of the studied groups I, II and II At the time of screening (Table 3), the concentration of $25(\mathrm{OH}) \mathrm{D}$ in almost all studied patients was regarded as VD deficiency, and the average values of this in patients of group I $24.1 \pm 4.3 \mathrm{ng} / \mathrm{ml}$, groups II and III $25.2 \pm 5.4 \mathrm{ng} / \mathrm{ml}$ and $24.9 \pm 5.1$, respectively. In each of the groups (group I $4(12 \%)$, group II - $6(14 \%)$, group III - $5(11 \%)$ ) several subjects had values of indicators that determined the presence of VD deficiency in patients.

Table 3

The content of $25(\mathrm{OH}) \mathrm{D}$ in the blood of the studied patients-

\begin{tabular}{|c|c|c|c|}
\hline $\begin{array}{c}\text { Level of 25(OH)D, } \\
\mathrm{ng} / \mathrm{ml}\end{array}$ & $\begin{array}{c}\text { Group I } \\
\mathrm{n}=32\end{array}$ & $\begin{array}{c}\text { Group II } \\
\mathrm{n}=44\end{array}$ & $\begin{array}{c}\text { Group III } \\
\mathrm{n}=46\end{array}$ \\
\hline Average starting level & \multicolumn{3}{|c|}{$24.7 \pm 4.9 \mathrm{ng} / \mathrm{ml}$} \\
\hline $\begin{array}{c}1 \text { day after the operat- } \\
\text { ing period }\end{array}$ & $24.4 \pm 4.6$ & $32.1 \pm 2.2 * \circ$ & $33.65 \pm 2.1 *$ \\
\hline $\begin{array}{c}2 \text { day after the operat- } \\
\text { ing period }\end{array}$ & $24.2 \pm 4.7$ & $32.2 \pm 1.9 * \circ$ & $33.1 \pm 2.4 * \wedge$ \\
\hline $\begin{array}{c}3 \text { day after the operat- } \\
\text { ing period }\end{array}$ & $24.1 \pm 4.2$ & $32.1 \pm 1.7 * \circ$ & $32.9 \pm 2.2 * \wedge$ \\
\hline
\end{tabular}

Note: $* p<0.05$ - differences between the indicator and the average starting level; ${ }^{\circ} p<0.05$ - differences between groups I and II; ${ }^{\wedge}$ - differences between groups I and III

When analyzing the level of VD in the blood in group I, no significant difference was found between the data at the screening stage and the level of $25(\mathrm{OH}) \mathrm{D}$ in the blood on the 1st, 2nd and 3rd day of treatment. During the entire observation period, 72 hours after surgery for primary ventral hernia in overweight patients, the values of $25(\mathrm{OH}) \mathrm{D}$ in the serum were almost unchanged, despite surgery and intensive care, was $24.4 \pm$ $\pm 4.6 \mathrm{ng} / \mathrm{ml}, 24.2 \pm 4.7 \mathrm{ng} / \mathrm{ml}$ and $24.1 \pm 4.2 \mathrm{ng} / \mathrm{ml}$ in patients of groups I, II and III, respectively, and were almost identical to the mean starting values.

In turn, in group II on the background of additional administration of cholecalciferol after determining at the stage of screening the fact of insufficiency of VD, the positive dynamics of the content of this indicator in the serum was determined. Thus, on the first day of the postoperative period, the concentration of VD in the blood of the subjects of group II was $32.1 \pm 2.2 \mathrm{ng} / \mathrm{ml}$, which was probably $(\mathrm{p}<0.05) 1.5$ times higher than the average starting values and probably $(\mathrm{p}<0.05)$ above the level of this indicator in patients of group I.

On the second and third days of hospital stay, an identical picture was determined. Thus, the level of VD in the blood of the subjects of group II was $32.2 \pm 1.9 \mathrm{ng} / \mathrm{ml}$ and $32.1 \pm 1.7 \mathrm{ng} / \mathrm{ml}$, respectively, which was likely $(\mathrm{p}<0.05)$ 
to 1.5 above the average starting values and probably $(p<0.05)$ above the concentration of this indicator in patients of group I. At the same time, none of the subjects had a level of $25(\mathrm{OH}) \mathrm{D}$ in the blood, which would indicate a deficiency.

When analyzing the dynamics of the content of VD in the serum of patients in group III, an identical picture was found in group II, but in the vast majority of patients this figure was slightly higher. So the level of VD in the blood was $33.6 \pm 2.1 \mathrm{ng} / \mathrm{ml}, 33.1 \pm 2.4 \mathrm{ng} / \mathrm{ml}$ and $32.9 \pm$ $\pm 2.2 \mathrm{ng} / \mathrm{ml}$ on the $1 \mathrm{st}, 2 \mathrm{nd}$ and 3rd days of intensive care, respectively, which was probably $(\mathrm{p}<0.05) 1.5$ above the mean starting values and probably $(\mathrm{p}<0.05)$ above the concentration of this indicator in patients of group I. However, none of the subjects was recorded level $25(\mathrm{OH}) \mathrm{D}$ in the blood, which would indicate a deficiency.

Thus, it can be noted that the additional administration of cholecaciferol in response to the determination at the screening stage of changes in the level of $25(\mathrm{OH}) \mathrm{D}$ in the blood of overweight patients who are scheduled for planned surgery for primary ventral hernia and perioperative period according to ERAS-protocol, promotes the positive dynamics of the content of $25(\mathrm{OH}) \mathrm{D}$ in the blood, which is an important element in improving metabolic changes caused by VD deficiency, improves the prognosis of this category of patients, and makes it possible to adequately implement an accelerated recovery program.

It can also be noted that when determining at the stage of screening in patients with BMI 25.0-29.9 vitamin $\mathrm{D}$ deficiency, it can be argued that there is an increased content of adipose tissue in the body, the amount of which is much higher than in standard cases with excess body weight due to the replacement of muscle tissue, i. e. the presence of patients with sarcopenic obesity. Given the role of PTH in calcium-phosphorus metabolism, as well as data from literature sources, which proved the direct dependence of its concentration on VD in the blood, we analyzed the concentration of PTH in the serum of the studied patients in the dynamics (Table 4).

Table 4

The content of parathyroid hormone in the blood of the studied patients

\begin{tabular}{|c|c|c|c|}
\hline $\begin{array}{c}\text { Level of PTH, } \\
\mathrm{pg} / \mathrm{ml}\end{array}$ & $\begin{array}{c}\text { Group I } \\
\mathrm{n}=32\end{array}$ & $\begin{array}{c}\text { Group II } \\
\mathrm{n}=44\end{array}$ & $\begin{array}{c}\text { Group III } \\
\mathrm{n}=46\end{array}$ \\
\hline $\begin{array}{c}\text { Average starting } \\
\text { level }\end{array}$ & \multicolumn{3}{|c|}{$114.3 \pm 13.6 \mathrm{pg} / \mathrm{ml}$} \\
\hline $\begin{array}{c}1 \text { day after the } \\
\text { operating period }\end{array}$ & $112.9 \pm 13.8$ & $79.2 \pm 8.9 * \circ$ & $65.6 \pm 8.1^{* \circ}$ \\
\hline $\begin{array}{c}\text { 2 day after the } \\
\text { operating period }\end{array}$ & $112.1 \pm 12.6$ & $77.4 \pm 7.1 * \circ$ & $64.9 \pm 9.6^{* \circ}$ \\
\hline $\begin{array}{c}3 \text { day after the } \\
\text { operating period }\end{array}$ & $111.8 \pm 14.2$ & $77.1 \pm 5.9$ & $65.2 \pm 7.4 * \circ$ \\
\hline
\end{tabular}

Note: ${ }^{*}-p<0.05$ - probable difference in relation to the average starting level

It is possible to note that at the time of screening of figure concentration of PTH in blood at all investigat- ed patients e xceeded the reference interval - 15.0 $65.0 \mathrm{pg} / \mathrm{ml}-2$ times from the upper limit of normal values and made accordingly $112.4 \pm 12.2 \mathrm{pg} / \mathrm{ml}, 116.7 \pm 14.6 \mathrm{pg} / \mathrm{ml}$ and $113.8 \pm 14.1 \mathrm{pg} / \mathrm{ml}$ in group I, group II and group III, with an average starting level of $114.3 \pm 13.6 \mathrm{pg} / \mathrm{ml}$. Subsequently, in group I on the 1st, 2nd and 3rd days of hospital stay, this figure was $112.9 \pm 13.8 \mathrm{pg} / \mathrm{ml}, 112.1 \pm$ $\pm 12.6 \mathrm{pg} / \mathrm{ml}$ and $111.8 \pm 14.2 \mathrm{pg} / \mathrm{ml}$, respectively, which almost coincided with the average starting values. In turn, in group II there was a decrease in the concentration of PTH in the blood of patients probably $(\mathrm{p}<0.05) 1.5$ times from the average starting level and probably $(p<0.05) 1.5$ times from the daily level in group I during the entire period of the examination with a tendency to decrease from the 1st to the 3rd day of the postoperative period. Thus, the level in the serum of this hormone was $79.2 \pm 8.9 \mathrm{pg} / \mathrm{ml}, 77.4 \pm 7.1 \mathrm{pg} / \mathrm{ml}$ and $77.1 \pm 5.9 \mathrm{pg} / \mathrm{ml}$ on the 1st, 2nd and 3rd and days of treatment, respectively, which exceeded the upper limit of normal values by $20 \%$.

In group III, there was a decrease in the concentration of PTH in the blood of patients probably $(p<0.05)$ in 2 times the mean starting level and probably $(\mathrm{p}<0.05)$ in 2 times the daily values in group I throughout the study period. Thus, the level in the serum of this hormone was $65.6 \pm 8.1 \mathrm{pg} / \mathrm{ml}, 64.9 \pm 9.6 \mathrm{pg} / \mathrm{ml}$ and $65.2 \pm 7.4 \mathrm{pg} / \mathrm{ml}$ on the 1st, 2nd and 3rd and days of intensive care. In contrast to the concentration of PTH in the serum of patients in group II, in group III almost $50 \%$ of patients had values of this hormone in the blood, which were interpreted as the norm (10-15\% less than the upper limit of normal values), which may be due to the additional appointment to the treatment algorithm of the ERAS protocol D-fructose-1,6-diphosphate sodium salt hydrate.

It can be assumed that the additional introduction of a phosphate source acted on the principle of feedback, i. e. the increase in blood phosphate levels decreased PTH secretion.

\section{Discussion}

In recent years, it has been established that adipose tissue is an independent active endocrine organ in which ad i pokines (hormones) are formed, including leptin, a leading biologically active agent. It is known that in conditions of hyperleptinemia there is hyperinsulinemia, endothelial dysfunction, hypertrophy of vascular wall cells, accumulation of cholesterol esters in foam cells, increase in the content of acute phase proteins, decrease in cholesterol levels and high-density lipoproteins.

Important is the fact that leptin has a negative effect on the enzyme of the final synthesis of VD in the kidneys and peripheral, including adipose, tissues [7, 11]. Thus, modern scientific data suggest that obesity can reduce the formation of VD, its deposition and accelerated destruction in adipocytes, reduce its bioavailability and the development of insufficiency and deficiency [11, 19]. However, it is thought that low VD levels contribute to obesity and/or prevent weight loss [9].

Before conducting a statistical analysis of the dynamics of leptinemia in the blood of patients in groups I, II and III, it should be noted that leptin is a signalling 
protein, the task of which is to regulate appetite and control the amount of stored fat in the body. It has an anorexigenic effect, i.e. it suppresses the appetite so that a person does not overeat - this is the most important signal to maint a in optimal weight and overall health, which occurs daily by the type of feedback. The predominant amount of leptin is secreted by hormonally active adipocytes in white adipose tissue, the size of adipocytes is an important determinant of leptin synthesis: large fat cells contain much more hormone than small adipocytes. Adipocytes secrete leptin into the blood in direct proportion to the mass of adipose tissue. The expression and secretion of leptin is also regulated by a variety of other factors: it increases under the influence of insulin, glucocorticoids a nd others. It is important to determine the condition, which was called "leptin resistance". With it, the brain simply stops reading the signal that there is enough fat, and continues to "store", perceiving leptin activity as hunger. Leptin resistance promotes the development of inflammatory processes, stimulates the adrenal glands to produce stress hormones and adversely affects most body functions, including fertility. In addition, in most cases, it becomes the starting point for the development of metabolic syndrome, a condition in which the body develops insulin resistance, and, in turn, type II diabetes.

It is known that in type II diabetes VD increases the sensitivity of cells to insulin and reduces the inflammatory response in the tissues of the pancreas $[4,20]$. Clinical studies have shown that hypovitaminosis VD is a risk factor for the development of insulin resistance regardless of obesity $[3,14]$.

When analyzing the data obtained by studying the level of IR in overweight patients who were treated with ERAS-program for surgery for primary ventral hernia, we obtained data indicating a possible link between VD and IR level, which is possible as a secondary effect of inhibition of leptin secretion by adipose tissue on the background of additional administration of VD, which is important in determining the optimal complex of perioperative intensive care.

Given the preliminary data obtained in determining the type of fat distribution using the calculation of VOI, lept in concentration in the blood and IR level, it becomes clear the effect of VD in serum on predicting the implementation of the accelerated recovery program in overweight patients scheduled for surgery for primary ventral hernia.

Since hypovitaminosis D has a negative effect on almost all types of metabolism, both primary and secondary, and based on the data we obtained on VOI figures, leptinemia and HOMA index, it is possible to predict the relationship between VD levels in the blood and obesity (In the patients we studied, the variant sarcopenic - due to a decrease in muscle mass - obesity).

Pathogenetic links linking obesity and VD deficiency, according to modern research, arise from the fact that, first, with an increased amount of adipose tissue in the body, VD, which is fat-soluble, is distributed in an increased volume, which leads to a decrease in its con- centration in blood plasma, and, secondly, obesity reduces the natural production of VD in the skin under the influence of sunlight, as overweight patients use in everyday life more closed clothes and spend less time outdoors $[4,20]$. We obtained data showing that the additional introduction of cholecaciferol in response to the determination at the screening stage in overweight patients who are scheduled for planned surgery for primary ventral hernia and perioperative period according to the ERAS protocol, contributes to the positive dynamics of the content $25(\mathrm{OH}) \mathrm{D}$ in the blood, which is an important element in improving metabolic changes caused by VD deficiency, improves the prognosis of this category of patients, and makes it possible to adequately implement an accelerated recovery program. It can also be noted that when determining at the stage of screening in patients with BMI 25.0-29.9 VD deficiency, it can be argued that there is an increased content of adipose tissue in the body, the amount of which is much greater than in standard cases of overweight body due to the replacement of muscle tissue, i. e. the presence of patients with sarcopenic obesity.

Given the obtained data, in order to further study the metabolic changes that were not identified in patients at the screening stage using a standard preoperative diagnostic algorithm, it was necessary to study the dynamics of parathyroid hormone in the blood in all subjects. It is known that PTH is important in regulating the level of calcium and phosphorus, maintaining their stable level in the body, stabilizing their level in the extracellular fluid. Its excretion is based on the principle of feedback, its concentration in the blood depends on the amount of calcium, magnesium phosphorus, vitamins A and D. In this case, secondary hyperparathyroidism, which is observed in obese patients in the absence of chronic renal failure or other somatic diseases, can be considered as a conseque nce of the long-standing VD deficiency [21]. According to many researchers, the level of $25(\mathrm{OH}) \mathrm{D}$ in the blood is inversely proportional to the concentration of PTH, which allows us to consider secondary hyperparathyroidis $\mathrm{m}$ a direct consequence of VD deficiency in obesity, with special emphasis on the duration of BMI, that is, chronic VD insufficiency has pathogenetic significance in this case $[3,10]$. Bila Zh. Ye. et al. in 2013, the journal "Effective Pharmacotherapy" published the results of a study which showed that at values of $25(\mathrm{OH}) \mathrm{D}$ less than $30 \mathrm{ng} / \mathrm{ml}$, a probable decrease in intestinal calcium absorption is accompanied by an increase in PTH secretion [22].

It can be assumed that the additional introduction of a phosphate source acted on the principle of feedback, i. e. the increase in blood phosphate levels decreased PTH secretion. Thus, we can conclude that in patients admitted to the hospital for planned surgery with excess body weight in the case of abdominal fat distribution in the anamnesis of more than 10 years in the vast majority of cases at the time of screening is determined by vitamin D deficiency with appropriate metabolic changes that are the consequences of secondary hyperparathyroidism, namely disorders of calcium-phosphorus metab- 
olism. The increase in the concentration of leptin in the blood contributes to the emergence of insulin resistance, which ex acerbates the vicious circle of changes in the body in obesity and makes it less promising to implement a program of accelerated recovery.

These dat a indicate the need for careful active dynamic monitoring in this category of patients for blood levels of VD, leptin, PTH when planning surgery and the appointment of a program of rapid recovery after surgery.

Study limitations. The small number of studied patients does not allow to disseminate the obtained data to the entire patient population, which requires further research.

Prospects for further research. Due to the increased risk of complications after elective surgery in patients with a history of overweight for more than 10 years, it is important to in-depth study of metabolic changes in the body to determine optimal management strategies for such patients and develop recommendations for clinical practice.

\section{Conclusions}

1. Based on current data, metabolic changes in the body, which are caused by the influence of the secretory function of adipose tissue as an independent endocrine organ, have a significant impact on the prognosis of the postoperative period. In patients with surgical profile with excess body weight lasting more than 10 years, it is important to determine the presence of sarcopenia, blood leptin and vitamin D concentration in the planning of patient management after planned surgery, which directly affects the possibility of implementing ERAS programs and quality of life as a remote prognosis of treatment.

2. Additional introduction to the treatment protocol of patients with overweight, BMI 25.0-29.9, lasting more tha $\mathrm{n} 10$ years in the history of cholecalciferol (perioperative period) is likely $(\mathrm{p}<0.05) 1.5$ times higher than the level of average starting values of $25(\mathrm{OH}) \mathrm{D}$ in the blood, does not affect the level of leptinemia and, accordingly, energy metabolism, but probably $(\mathrm{p}<0.05)$ reduces insulin resistance by 1.5 times probably $(\mathrm{p}<0.05)$ reduces the level of average starting values of PTH in the blood.

3. Additional introduction to the treatment protocol of cholecalciferol (perioperative period) and a solution of D-fructose-1,6-diphosphate sodium salt hydrate (postoperative period) identically affects the dynamics of level $25(\mathrm{OH}) \mathrm{D}$, leptin in the blood, and the HOMA index, probably $(\mathrm{p}<0.05)$ reduces the level of average starting values of PTH in the blood by 2 times.

4. In the classical approach to the implementation of the ER AS program in overweight patients, BMI 25.0-29.9, lasting more than 10 years in the anamnesis, with identified at the stage of screening for insufficiency/ deficiency of $25(\mathrm{OH}) \mathrm{D}$, the probability of successful its implementation is $63 \%$. When 7000 IU/day of cholecalciferol is added to the treatment protocol, the probability of successful implementation of the ERAS program is $81 \%$. When adding to the treatment protocol $7000 \mathrm{IU} /$ day of chole c alciferol and a solution of D-fructose-1,6diphosphate sodium salt hydrate intravenously $150 \mathrm{mg} / \mathrm{kg}$ of ideal body weight 2 times a day at a rate of $10 \mathrm{ml}$ per minute for the first 3 days of the postoperative period the same mode of introduction, the probability of successful implementation of the ERAS-program is $96 \%$.

\section{Conflict of interest}

The authors declare that they have no conflicts of interest.

\section{References}

1. Gil, Á., Plaza-Diaz, J., Mesa, M. D. (2018). Vitamin D: Classic and Novel Actions. Annals of Nutrition and Metabolism, 72 (2), 87-95. doi: http://doi.org/10.1159/000486536

2. Gunto n, J. E., Girgis, C. M. (2018). Vitamin D and muscle. Bone Reports, 8, 163-167. doi: http://doi.org/10.1016/ j.bonr.2018.04.004

3. Srinath, K. M., Shashidhara, K. C., Reddy, G. R., Basavegowda, M. (2016). Pattern of vitamin D status in prediabetic individuals: a case control study at tertiary hospital in South India. International Journal of Research in Medical Sciences, 4, $1010-1015$. doi: http://doi.org/10.18203/2320-6012.ijrms20160706

4. Dzik, K. P., Kaczor, J. J. (2019). Mechanisms of vitamin D on skeletal muscle function: oxidative stress, energy metabolism and anabolic state. European Journal of Applied Physiology, 119 (4), 825-839. doi: http://doi.org/10.1007/s00421-019-04104-x

5. Collins, K. H., Herzog, W., MacDonald, G. Z., Reimer, R. A., Rios, J. L., Smith, I. C. et. al. (2018). Obesity, Metabolic Syndrome, and Musculoskeletal Disease: Common Inflammatory Pathways Suggest a Central Role for Loss of Muscle Integrity. Frontiers in Physiology, 9. doi: http://doi.org/10.3389/fphys.2018.00112

6. Wacker, M., Holick, M. F. (2013). Sunlight and Vitamin D. Dermato-Endocrinology, 5 (1), 51-108. doi: http://doi.org/10.4161/ derm. 24494

7. Richard, A., Rohrmann, S., Quack Lötscher, K. (2017). Prevalence of Vitamin D Deficiency and Its Associations with Skin Color in Pregnant Women in the First Trimester in a Sample from Switzerland. Nutrients, 9 (3), 260. doi: http://doi.org/10.3390/nu9030260

8. Elder, D. H. J., Singh, J. S. S., Levin, D., Donnelly, L. A., Choy, A.-M., George, J. et. al. (2015). Mean HbA1cand mortality in diabetic individuals with heart failure: a population cohort study. European Journal of Heart Failure, 18 (1), 94-102. doi: http:// doi.org/10.1002/ejhf.455

9. Pereira-Santos, M., Costa, P. R. F., Santos, C. A. S. T., Santos, D. B., Assis, A. M. O. (2016). Obesity and vitamin D deficiency: is there an association? Obesity Reviews, 17 (5), 484. doi: http://doi.org/10.1111/obr.12393

10. Srikanth, P., Chun, R. F., Hewison, M., Adams, J. S., Bouillon, R. et. al. (2016). Associations of total and free 25OHD and 1,25(OH)2D with serum markers of inflammation in older men. Osteoporosis International, 27 (7), 2291-2300. doi: http://doi.org/ $10.1007 / \mathrm{s} 00198-016-3537-3$ 
11. Zhai, H.-L., Wang, N.-J., Han, B., Li, Q., Chen, Y., Zhu, C.-F. et. al. (2016). Low vitamin D levels and non-alcoholic fatty liver disease, evidence for their independent association in men in East China: a cross-sectional study (Survey on Prevalence in East China for Metabolic Diseases and Risk Factors (SPECT-China)). British Journal of Nutrition, 115 (8), 1352-1359. doi: http:// doi.org/10.1017/s0007114516000386

12. Beilfuss, A., Sowa, J.-P., Sydor, S., Beste, M., Bechmann, L. P., Schlattjan, M. et. al. (2014). Vitamin D counteracts fibrogenic TGF- $\beta$ signalling in human hepatic stellate cells both receptor-dependently and independently. Gut, 64 (5), 791-799. doi: http:// doi.org/10.1136/gutjnl-2014-307024

13. Druzhilov, M. A., Beteleva, Y. E., Kuznetsova, T. Y. (2014). Epicardial adipose tissue thickness - an alternative to waist circumference as a stand-alone or secondary main criterion in metabolic syndrome diagnostics? Russian Journal of Cardiology, 3, 76-81. doi: http://doi.org/10.15829/1560-4071-2014-3-76-81

14. Bowes, C. D., Lien, L. F., Butler, J. (2019). Clinical aspects of heart failure in individuals with diabetes. Diabetologia, 62 (9), 1529-1538. doi: http://doi.org/10.1007/s00125-019-4958-2

15. Joubert, M., Manrique, A., Cariou, B., Prieur, X. (2019). Diabetes-related cardiomyopathy: The sweet story of glucose overload from epidemiology to cellular pathways. Diabetes \& Metabolism, 45 (3), 238-247. doi: http://doi.org/10.1016/j.diabet.2018.07.003

16. Bottle, A., Kim, D., Hayhoe, B., Majeed, A., Aylin, P., Clegg, A., Cowie, M. R. (2019). Frailty and co-morbidity predict first hospitalisation after heart failure diagnosis in primary care: population-based observational study in England. Age and Ageing, 48 (3), 347-354. doi: http://doi.org/10.1093/ageing/afy194

17. Leung, P. (2016). The Potential Protective Action of Vitamin D in Hepatic Insulin Resistance and Pancreatic Islet Dysfunction in Type 2 Diabetes Mellitus. Nutrients, 8 (3), 147. doi: http://doi.org/10.3390/nu8030147

18. McMullan, C. J., Borgi, L., Curhan, G. C., Fisher, N., Forman, J. P. (2017). The effect of vitamin D on renin-angiotensin system activation and blood pressure. Journal of Hypertension, 35 (4), 822-829. doi: http://doi.org/10.1097/hjh.0000000000001220

19. Ye, Z., Sharp, S. J., Burgess, S., Scott, R. A., Imamura, F., Langenberg, C. et. al. (2015). Association between circulating 25-hydroxyvitamin D and incident type 2 diabetes: a mendelian randomisation study. The Lancet Diabetes \& Endocrinology, 3 (1), 35-42. doi: http://doi.org/10.1016/s2213-8587(14)70184-6

20. Flier, J. S., Maratos-Flier, E. (2017). Leptin's Physiologic Role: Does the Emperor of Energy Balance Have No Clothes? Cell Metabolism, 26 (1), 24-26. doi: http://doi.org/10.1016/j.cmet.2017.05.013

21. Al Qarni, A. A., Joatar, F. E., Das, N., Awad, M., Eltayeb, M., Al-Zubair, A. G. et. al. (2017). Association of Plasma Ghrelin Levels with Insulin Resistance in Type 2 Diabetes Mellitus among Saudi Subjects. Endocrinology and Metabolism, 32 (2), $230-240$. doi: http://doi.org/10.3803/enm.2017.32.2.230

22. Cohen, P., Spiegelman, B. M. (2016). Cell biology of fat storage. Molecular Biology of the Cell, 27 (16), $2523-2527$. doi: http://doi.org/10.1091/mbc.e15-10-0749

23. Esfahani, M., Movahedian, A., Baranchi, M., Goodarzi, M. T. (2015). Adiponectin: an adipokine with protective features against metabolic syndrome. Iranian Journal of Basic Medical Sciences, 18 (5), 430-442.

24. Celermajer, D. S., Sorensen, K. E., Gooch, V. M., Spiegelhalter, D. J., Miller, O. I., Sullivan, I. D. et. al. (1992). Non-invasive detection of endothelial dysfunction in children and adults at risk of atherosclerosis. The Lancet, 340 (8828), 1111-1115. doi: http://doi.org/10.1016/0140-6736(92)93147-f

Received date 06.08.2020

Accepted date 11.09.2020

Published date 30.09.2020

Hlib Diachenko, Assistant, Department of Emergency Medicine, Anesthesiology and Intensive Care, Kharkiv National Medical University, Nauky ave., 4, Kharkiv, Ukraine, 61022

E-mail: dryu.volkova@gmail.com

Yuliya Volkova, MD, Professor, Head of Department, Department of Emergency Medicine, Anesthesiology and Intensive Care, Kharkiv National Medical University, Nauky ave., 4, Kharkiv, Ukraine, 61022

E-mail: dryu.volkova@gmail.com 